\title{
AVALIAÇÃO DO DESGASTE DE DIAMANTES SINTÉTICOS NA DRESSAGEM (AFIAÇÃO) DE REBOLOS
}

\author{
Armínio Frech Junior ${ }^{1}$
}

\section{Eduardo Carlos Bianchi ${ }^{2}$}

\section{Paulo Roberto Aguiar ${ }^{3}$}

\begin{abstract}
RESUMO: Rebolos são ferramentas abrasivas utilizadas na fabricação de peças de precisão na indústria mecânica. Periodicamente os rebolos devem ser dressados (afiados) por ferramentas denominadas por dressadores. Estes são, normalmente, fabricados com diamantes naturais que estão cada vez mais escasso e oneroso. Pelo que foi constatado em contato com fabricantes de dressadores, o volume de dressadores e outras ferramentas abrasivas é substancialmente elevado, o que inviabiliza a utilização destes. A proposta deste trabalho foi de se estudar um diamante sintético que possa substituir, com vantagens técnicas e econômicas os tradicionais diamantes naturais. O diamante em questão foi avaliado ao longo da sua vida útil e mostrou-se ser resistente e com plenas potencialidades de ser utilizados na fabricação de dressadores.
\end{abstract}

Palavras-chave: Meio ambiente. Preocupação ambiental. Dressadores. Ferramentas abrasivas.

\footnotetext{
${ }^{1}$ Aluno de Engenharia Mecânica, UNESP, Bolsista FAPESP. arfrech@gmail.com

${ }^{2}$ Engenheiro Mecânico, UNESP, Professor Titular. bianchi@feb.unesp.br

${ }^{3}$ Engenheiro Eletricista, UNESP, Professor Titular. aguiarpr@feb.unesp.br
} 


\section{INTRODUÇÃO}

A retificação é um processo de fabricação em que se utiliza uma grande quantidade de fluído de corte, cujas funções são: lubrificação, reduzindo deste modo a geração de calor; refrigeração, eliminando o calor gerado; retirada do cavaco na zona de corte; proteção da máquina-ferramenta e da peça à corrosão atmosférica, entre outros.

A energia no processo de retificação é utilizada na formação do cavaco, deformações e atrito. Nas temperaturas de pico, o material da peça chega a aproximar-se da temperatura de fusão mas, como o tempo de contato rebolo/peça é extremamente reduzido, tais temperaturas estão localizadas nos planos de cisalhamento dos cavacos e o cavaco não chega a fundir, porém ocasiona variações metrológicas na qualidade final do produto (DHAR et al, 2007; LEE et al, 2002).

O efeito das elevadas temperaturas atingidas durante o processo de retificação deve ser evitado. Apesar das muitas vantagens encontradas na utilização de fluidos de corte durante a usinagem, estes apresentam desvantagens econômicas e ecológicas que tem feito com que novas pesquisas, buscando a diminuição de fluidos ou até mesmo a eliminação deste, sejam realizadas (SAHM, D.; SCHNEIDER, T., 1996).

O comportamento de qualquer processo de retificação é muito dependente do desempenho da ferramenta. Esse desempenho pode mudar de maneira significativa durante o processo de retificação e isso dificulta a previsão a respeito do comportamento do processo durante seu andamento. (GAO et al., 2007). O rebolo, além de sofrer alterações durante o processo de retificação, pode perder suas condições ideais em seu próprio processo de fabricação.

Assim, os resultados da retificação estão diretamente relacionados com as condições topográficas da superfície de trabalho do rebolo. Estando essas condições alteradas, a operação de dressagem passa a ser fundamental ao processo.

Dressagem é o processo de condicionamento da superfície do rebolo visando sua remodelação quando o mesmo perdeu sua forma original pelo desgaste. (XUE et al., 2002). É a operação conjunta de perfilamento e afiação dos rebolos convencionais. (MARINESCU et al., 2007). 
As condições de dressagem podem provocar uma grande influência no desempenho da operação de retificação. Para se ter uma ideia dessa influência, basta dizer que as forças de retificação podem variar cerca de 500\%, apenas variando-se as condições de dressagem em um mesmo tipo de operação (OLIVEIRA, 1988).

A ferramenta utilizada para a recuperação do rebolo é o dressador. Devido ao grande número de variáveis que influenciam o processo, existe um número muito grande de ferramentas (dressadores) que já foram desenvolvidas, e cada uma dessas ferramentas é responsável pela abrangência de um número limitado de casos.

Sendo o conhecimento a respeito da operação de dressagem pouco explorado, com bibliografias limitadas, este ainda é superficial. Para aprofundar este conhecimento acerca de um tipo específico de dressador, dentre os vários existentes, propõe-se neste trabalho a realização de ensaios monitorados com dressadores de ponta única, sendo o material de estudo o diamante sintético.

\section{DESENVOLVIMENTO}

Foram realizados 3 ensaios com três dressadores com o diamante CVD Sintético.

A taxa de desgaste encontrada pela curva linear da figura 22 foi de 0,3549 $\mathrm{mm}^{2}$ /passada, com um ajuste linear de 0,9877, mostrando uma boa linearização dos dados. O número máximo de passadas foi de 156, quando ocorreu o contato do metal com o rebolo, ocasionando o faiscamento e a interrupção do ensaio. A partir da passada 94 passou a ocorrer desprendimento de grandes cavacos do rebolo.

Nas figuras 1, 2, 3 e 4 estão mostradas as imagens mais relevantes retiradas do diamante CVD Sintético na posição horizontal para o primeiro ensaio. 


\section{Periódica Eletránica

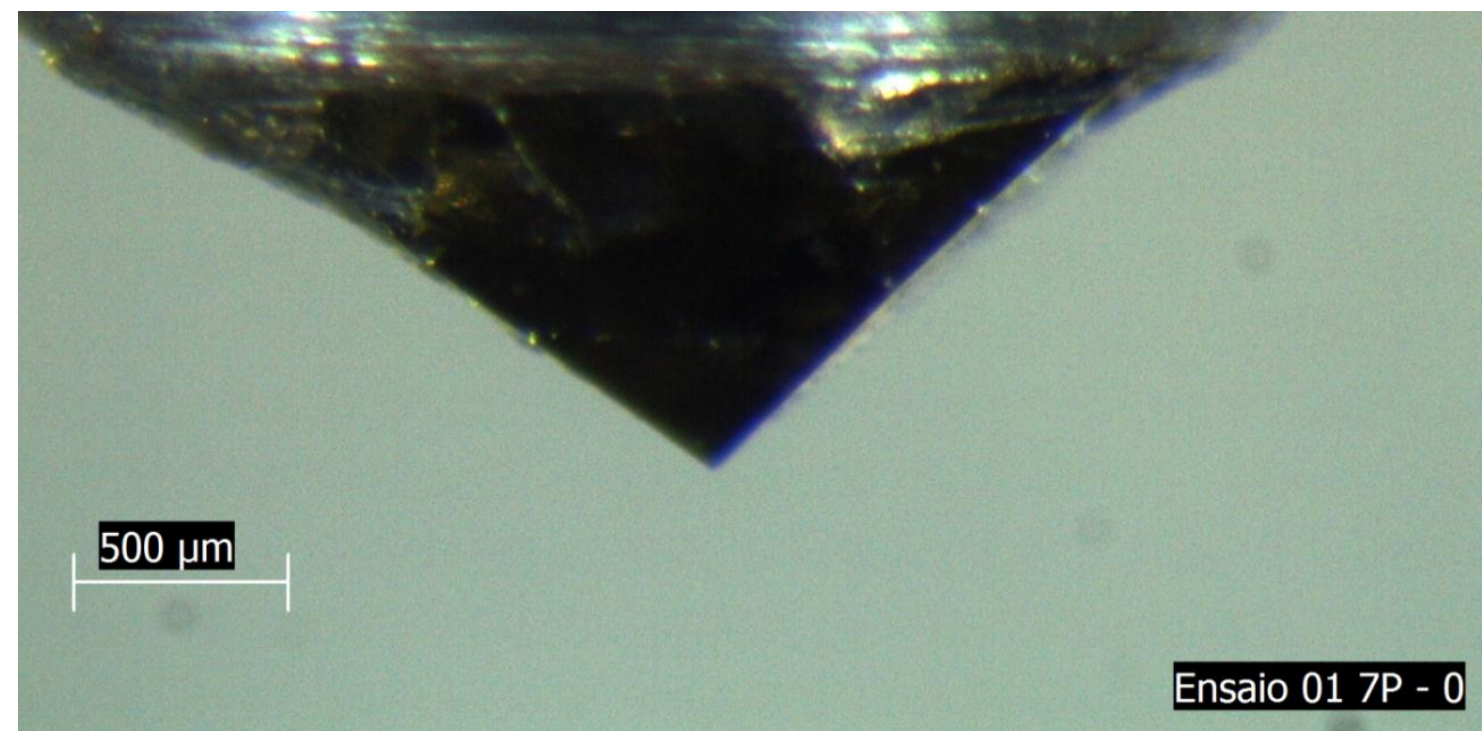

Figura 1 - Diamante CVD sintético com nenhuma passada, posição horizontal no ensaio um.

$\mathrm{Na}$ figura 1 observa-se o diamante ainda intacto, sem nenhuma ter sofrido qualquer dressagem. Observa-se também ser um diamante com uma tonalidade escura, característica dos diamantes sintéticos.

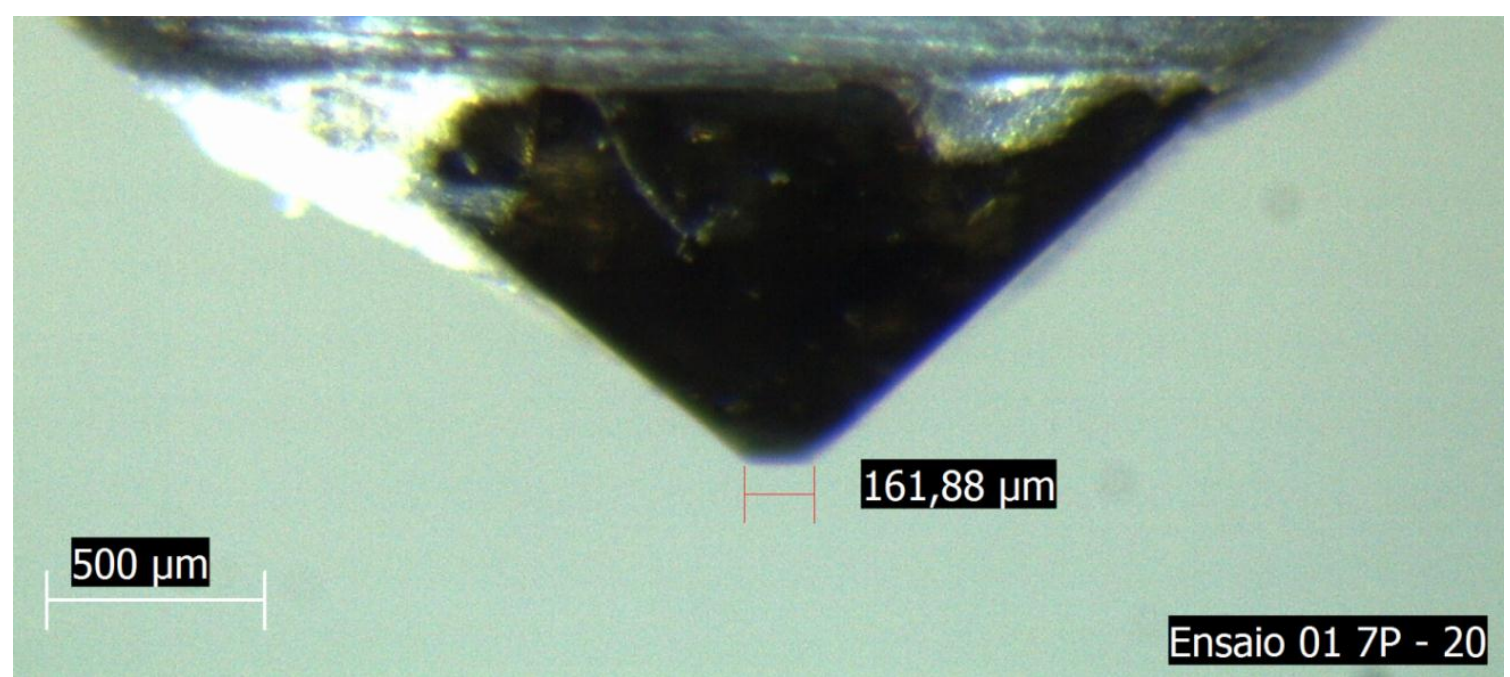

Figura 2 - Diamante CVD sintético com 20 passadas, posição horizontal no ensaio um.

A figura 2 mostra o diamante sintético após as primeiras 20 passadas. Observa-se claramente o desgaste em sua ponta, mostrando um comprimento de desgaste aparente de $161,88 \mu \mathrm{m}$. 


\section{Periódica Eletranica

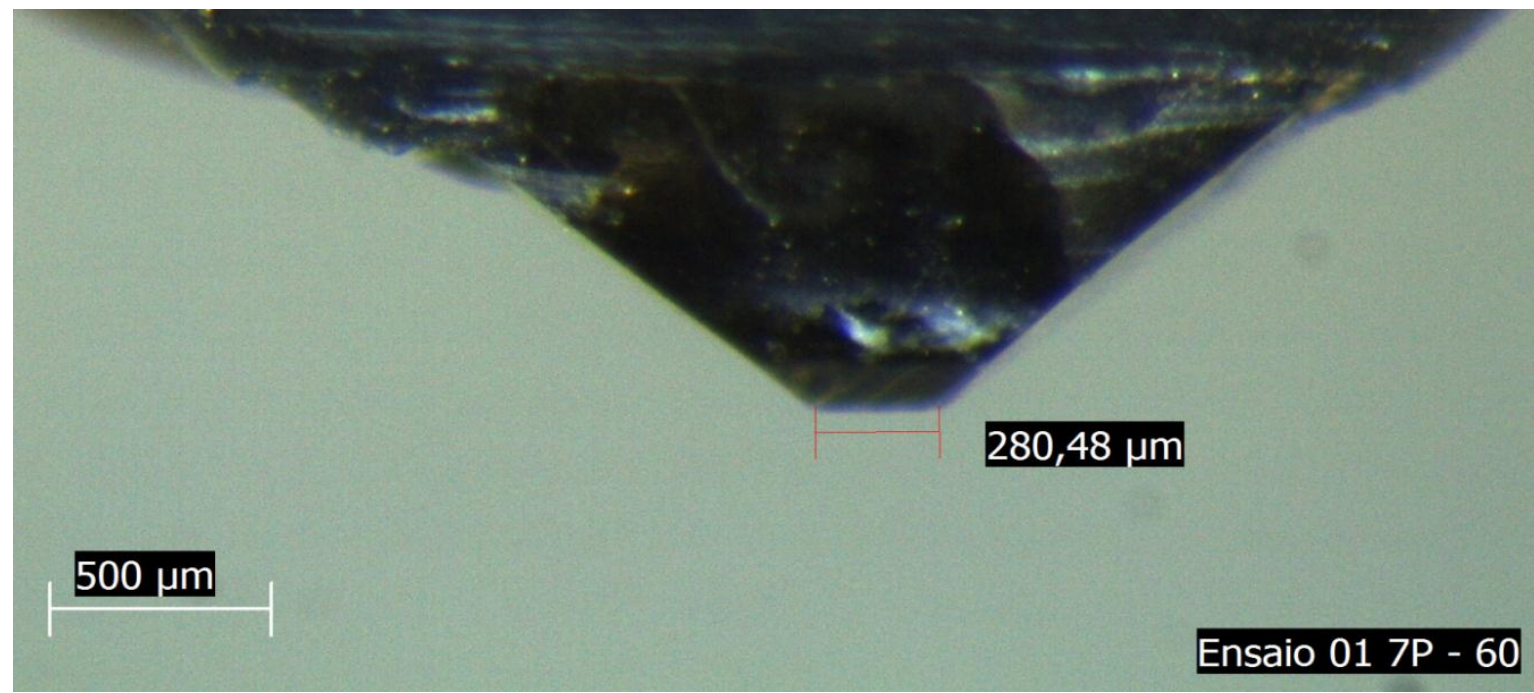

Figura 3 - Diamante CVD sintético com 60 passadas, posição horizontal no ensaio um.

A figura 3 mostra o diamante sintético após 60 passadas. A figura mostra que o comprimento de desgaste cresceu bastante com relação ao obtido pela figura 4, com uma medida de 280,48 $\mu \mathrm{m}$. O diamante também já mostra uma seção de desgaste muito mais aparente que o da figura anterior. O diamante também já apresenta certas distorções, quando comparado com o da figura 2, devidas principalmente ao sucessivo aumento da temperatura ocasionado pelo aumento de contato entre o diamante o rebolo.

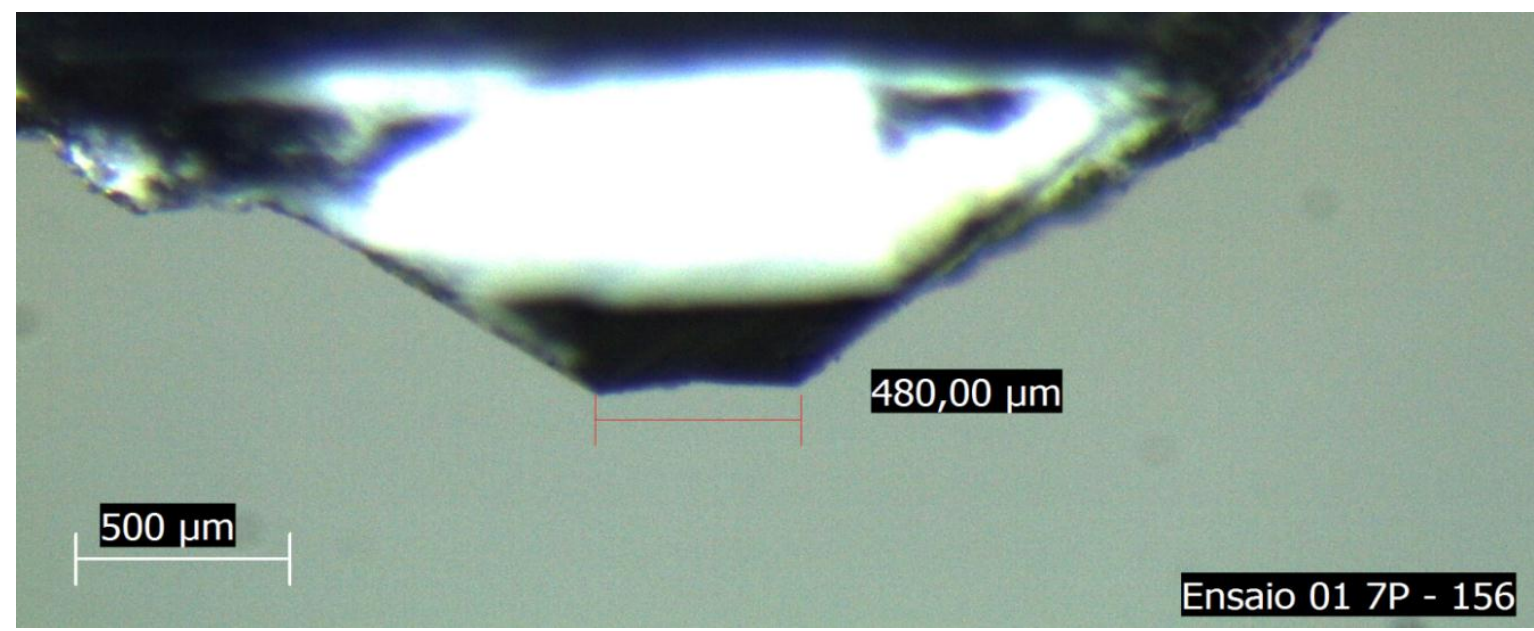

Figura 4 - Diamante CVD sintético ao final do ensaio um, com 156 passadas na posição horizontal. 
A figura 4 mostra o fim do primeiro ensaio, com o diamante com 156 passadas. Observa-se que o comprimento de desgaste é bem maior que das figuras 24 e 25, com 480,00 $\mu \mathrm{m}$. O diamante também apresenta uma grande área de desgaste. A parte esbranquiçada da figura 26 é o reflexo da solda derretida, formada de estanho, cujo qual prendia o termopar no dressador. Mesmo com o reflexo dá para observar bem a área desgastada.

Nas figuras 5, 6, 7, 8, 9, 10 e 11 foram colocadas as três imagens referentes ao desgaste para cada 20 passadas dos três ensaios até a passada 140.

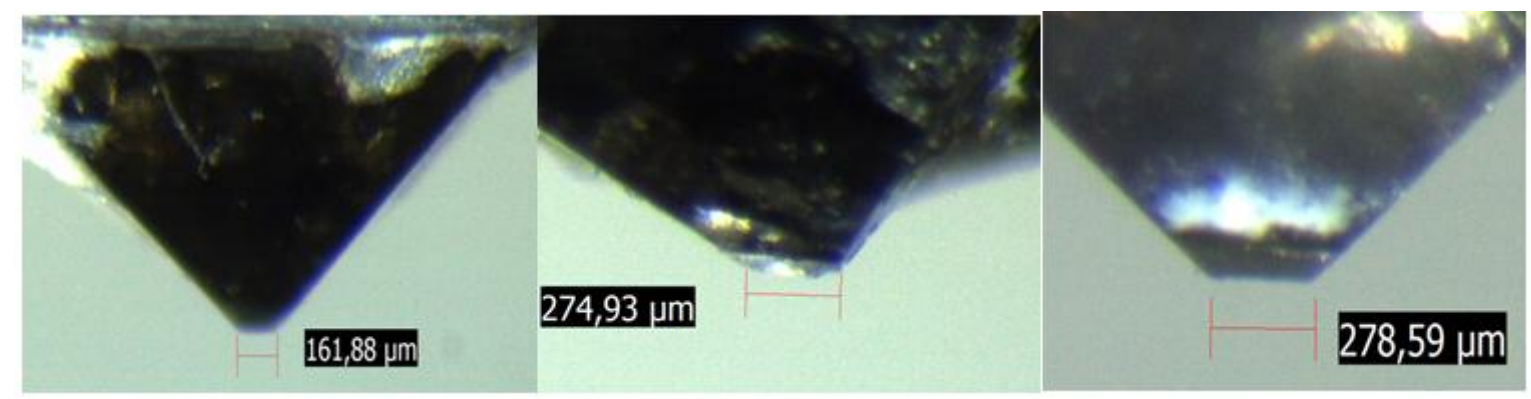

Figura 5 - Ensaios 01, 02 e 03 com 20 passadas na posição horizontal.

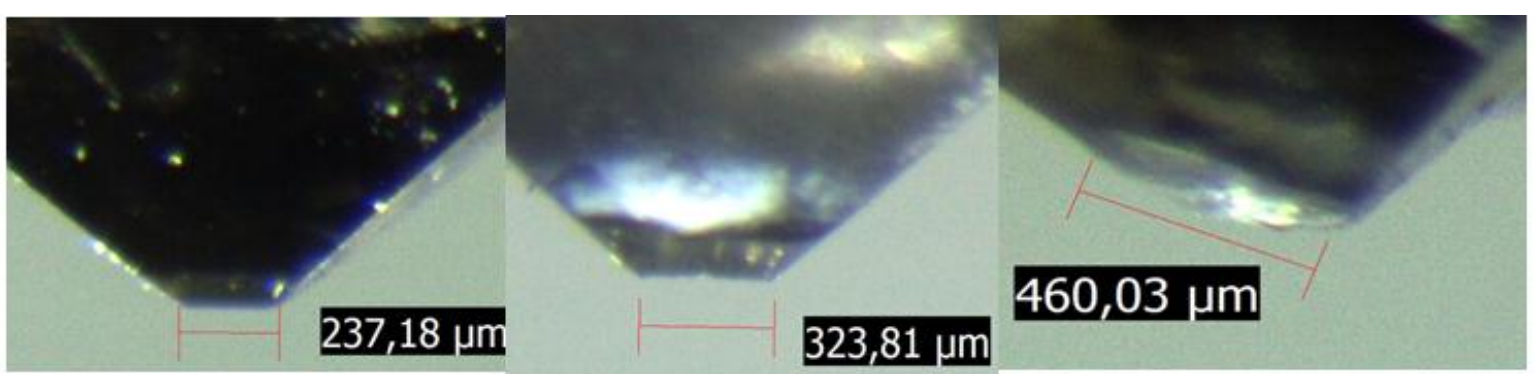

Figura 6 - Ensaios 01, 02 e 03 com 40 passadas na posição horizontal.

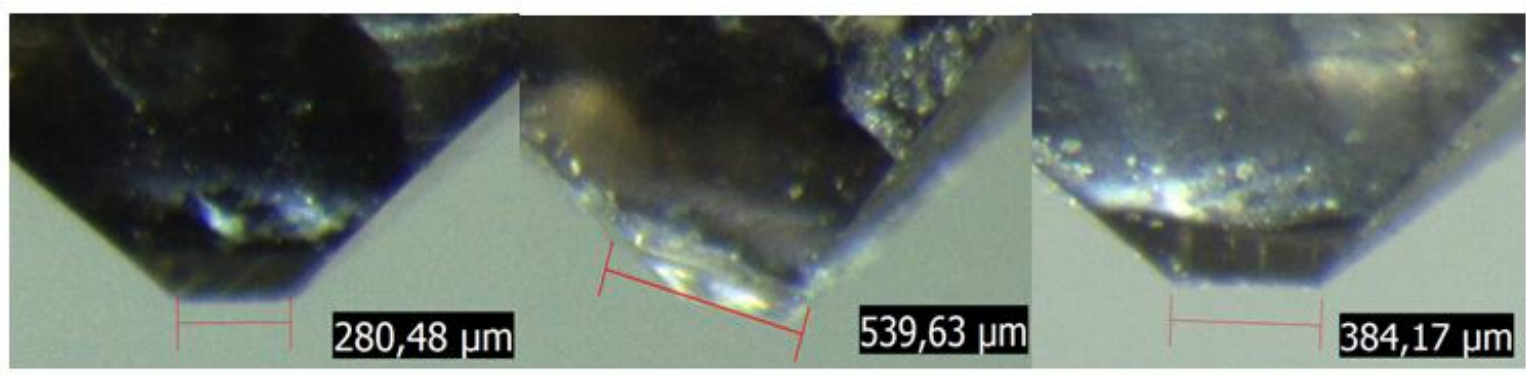

Figura 7 - Ensaios 01, 02 e 03 com 60 passadas na posição horizontal.

VIII Fórum Ambiental da Alta Paulista, v. 8, n.1, 2012, p. 10-18. 

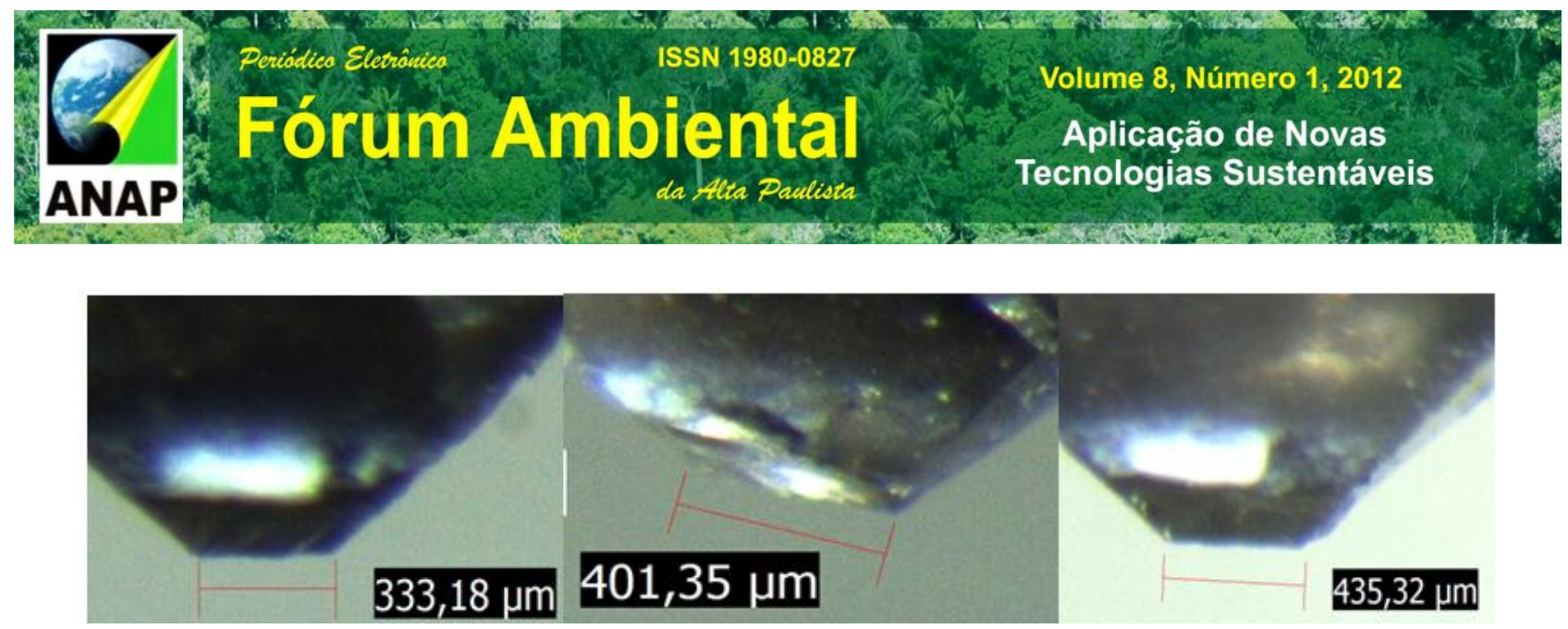

Figura 8 - Ensaios 01, 02 e 03 com 80 passadas na posição horizontal.

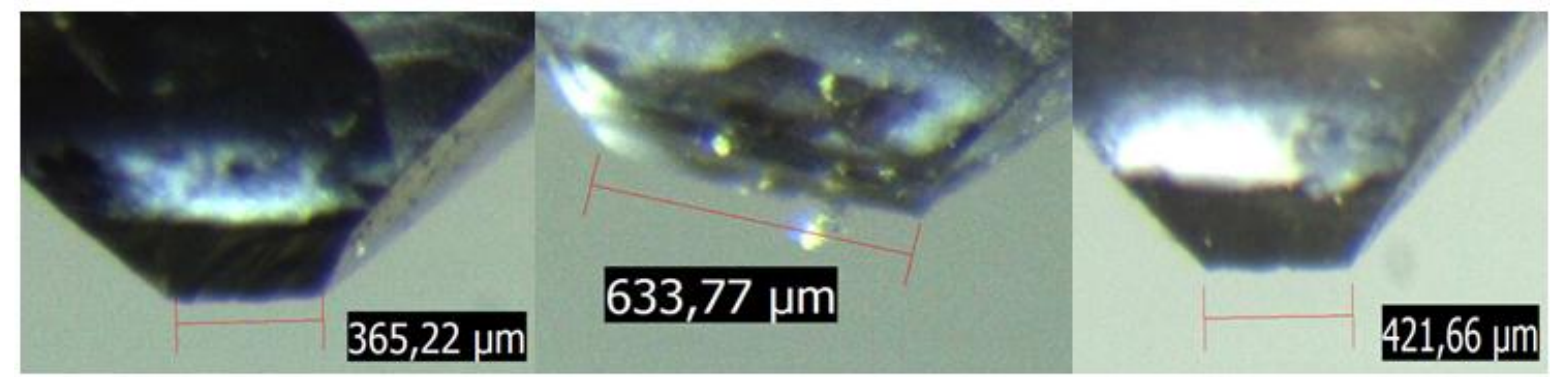

Figura 9 - Ensaios 01, 02 e 03 com 100 passadas na posição horizontal.

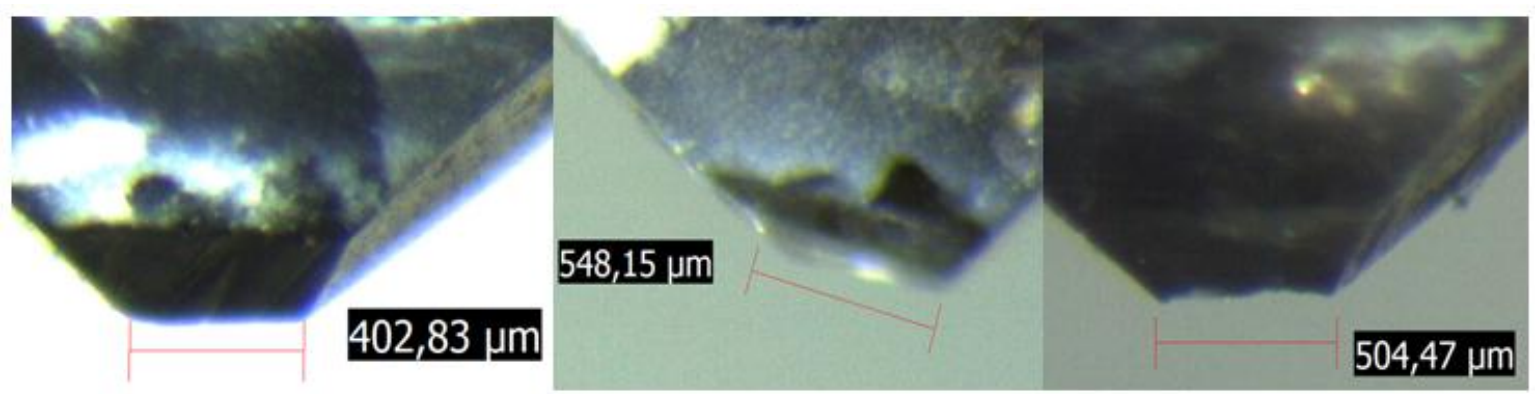

Figura 10 - Ensaios 01, 02 e 03 com 120 passadas na posição horizontal.
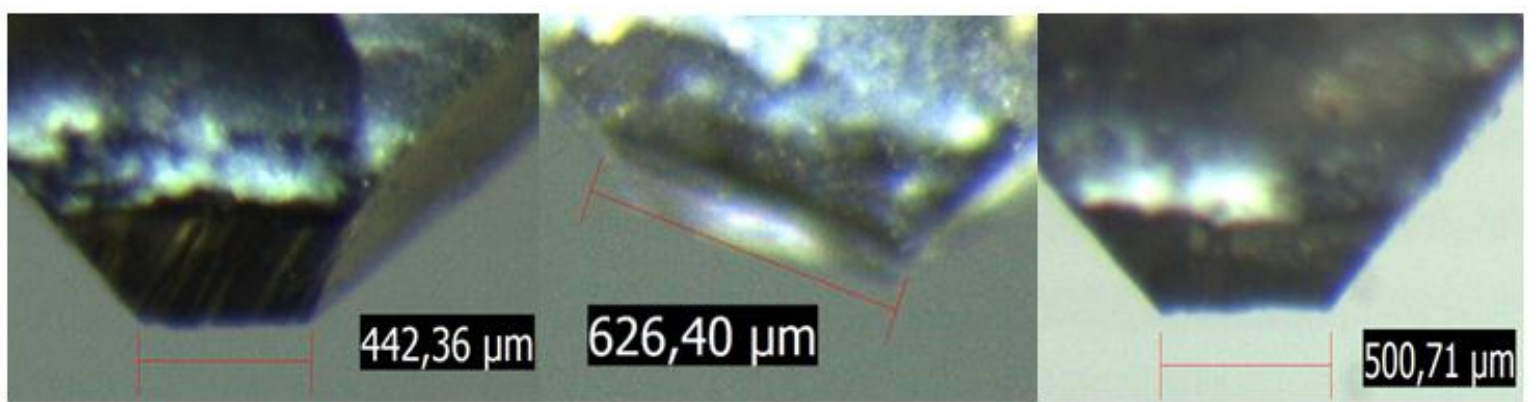

Figura 11 - Ensaios 01, 02 e 03 com 140 passadas na posição horizontal. 


\section{CONCLUSÕES}

De acordo com os dados obtidos, foi possível verificar o comportamento do desgaste do diamante sintético a ser utilizado na fabricação de dressadores com amplas possibilidades de ser um excelente substituto ao tradicional diamante natural, que é cada vez mais escasso.

\section{AGRADECIMENTOS}

Manifestamos nossos agradecimentos à FAPESP pelo apoio financeiro.

\section{REFERÊNCIAS}

DHAR, N., ISLAM, S. and KAMRUZZAMAN, M., 2007, "Effect of Minimum Quantity Lubrication (MQL) on Tool Wear, Surface Roughness and Dimensional Deviation in Turning AISI-4340 Steel", G.U. Journal of Science, vol. 20, pp. 23-32.

GAO, ROBERT X., Monitoring Systems for Grinding Processes, Springer Series in Advanced Manufacturing, pp. 83-107, 2007.

MARINESCU, I. D., HITCHINER, M., UHLMANN, E., ROWE, W. B. \& INASAKI, I., Handbook of machining with grinding wheels. 1a Ed. Boca Raton, FL: CRC Press, Taylor \& Francis Group, 2007.

OLIVEIRA, J. F. G. Análise da ação do macroefeito de dressamento de rebolos no desempenho do processo de retificação. Tese de Doutorado - USP, São Carlos,SP, Brasil, 1988. 
SAHM, D., SCHNEIDER, T., 1996, "The production without coolant is interesting and must be more known", Machines and Metals Magazine (367), 38-55.

XUE, L., NAGHDY, F., COOK, C., Monitoring of wheel dressing operations for precision grinding, FIEEE International Conference on Industrial Technology, Bangkok, pp. 12961299, 2002. 